\title{
Performance analysis of means of mitigating overhead power lines wires sag designed in Ukraine and USA
}

\section{Anatoliy Ukrayinets, Volodymyr Shesterenko, Volodymyr Romaniuk}

National University of Food Technologies, Kyiv, Ukraine

Keywords:

Thermal

Compensation

Sag

Span

Wire

Power line

Article history:

Received 12.03.2019

Received in revised form 28.05.2019

Accepted 30.05.2019

\section{Corresponding} author:

Volodymyr

Shesterenko

E-mail:

shest.iren.co@ukr.net

\section{DOI:}

$10.24263 / 2310-1008-$

2019-7-1-14

\section{Abstract}

Introduction. Conducting a comprehensive analysis of methods and tasks for ensuring the effective implementation of innovative thermal compensating devices.

Materials and methods. Physical and mathematical modeling of processes, the principles of the theory of automatic control, the theory of fuzzy logic were used.

Results and discussion. The compensation of overhead power lines wires sag creates conditions under which it is possible either to increase spans, or to reduce the height of the towers while preserving the existing estimated spans. As a result, the specific consumption of the supports, linear fittings, insulation is reduced, and the time for construction of the power lines is also reduced. Taking into account the existing norms, it is possible to increase the span of the power line of different voltage classes by $7-10 \%$.

As a result of the conducted research, a method for calculation and optimization of existing devices for thermal compensation of power lines wires sag has been developed. A multifunctional device for compensation of temperature arcs of sagging of power lines, which allows to optimize both working and projected power lines is proposed.

Conclusions. The results of this work should be used in electrical networks with overhead power lines of all voltages. The Ukrainian thermal compensator is a new class of equipment for power lines, which solves the problem of temperature extension of wires, using a material that responds to the temperature changes by changing its geometric shape and size and is more reliable than the American one. 


\section{Introduction}

The purpose of this work is the development and analysis of multifunctional devices for compensation of temperature sagging of power lines wires, optimization of their parameters, analysis of combined work of wires in spans with such devices. The results of this research can be applied to power lines of any voltage ratings.

Increasing the efficiency of operation of electrical networks by introducing the latest technologies and equipment requires solving a number of complex scientific and practical problems, among which the problem of imperfect regulatory framework and insufficient information provision on innovation activity is central.[1,3,4,13,15,17].

\section{Materials and methods}

Increasing the length of the power lines spans or reducing the height of the towers while maintaining the existing estimated spans can significantly reduce the cost of building materials, linear fittings, isolation during the construction of power lines. Optimization of power lines can be achieved by using special devices that increase the tension force in the wires with increasing temperature and reduce the temperature induced sag of the wires. Such devices by the authors were called thermal compensators of power line arcs of sagging. The active thermocompensation of the arcs of sagging can be achieved with the help of force elements, which are fastened to the wire and act on it. The production of devices with negative temperature extensions for a certain temperature range became possible after the discovery of the unique property of some alloys to "memorize" the shape $[1,2,4,12,14,16]$.

Most clearly this property is expressed in the alloy of nickel with titanium - nitinol. The sample of this alloy is heated for transition to a high-temperature modification and in this state it is given a certain shape. Then the alloy is straightened out below critical temperature and is transfered to another, low temperature phase. This phenomenon reminds the thermoelastic transformation. Due to the fact that the material with a "shape memory effect" (SME) has a significant impact strength, a high endurance limit, easy to forge, efficiently dampens vibration, does not corrode even in seawater, does not oxidize when heated to a temperature of $880^{\circ} \mathrm{K}$, does not crack under stress and is non-magnetic, from this material it is possible to make a power element in the form of a thread with the length 1-8 $\mathrm{m}$ and to attach it parallel to the segment of the wire in each span $[2,4,15,17]$. (Patent of Ukraine №17994, F03G 7/06./Ukrayinets A.I. Shesterenko V.Ye., Patent of Ukraine №19634,/Ukrayinets A.I. Shesterenko V.Ye., Patent of Ukraine № 42169, H01R 11/00./Ukrayinets A.I., Shesterenko V.Ye., USA Patents №US 2014/0021327 A1, №6864421B1).

\section{Results and discussion}

The main requirement for the operation of the thermal compensator with SME: the length of the section of the wire, parallel to which the thermal compensator attaches, must be equal to the length of the thermal compensator in the unloaded state, increased by the magnitude of the maximum permissible deformation of the compensator in the area parallel to the wire, and the value of the maximum possible deformation of the thermal compensator must be equal to the absolute elongation of the wire in the given temperature range $[1,2,4]$. 


\section{American thermal compensator}

The Sagging Line Mitigator (SLIM) is able to automatically compensate for sag in a suspended or hanging line, such as a power line. It uses a material that changes its dimensions as a function of temperature. One such material is shape memory alloy (SMA) which undergoes a phase transformation upon temperature change and produces a significant change in size and geometry. In this invention, the SMA will contract as its temperature increases. The contraction of the SMA produces a pulling force (increasing tensile force) which is indirectly transferred to the suspended line, effectively pulling in the slack and reducing sag. SLIM uses at least one lever to amplify the SMA length change and transfer it to the suspended line.

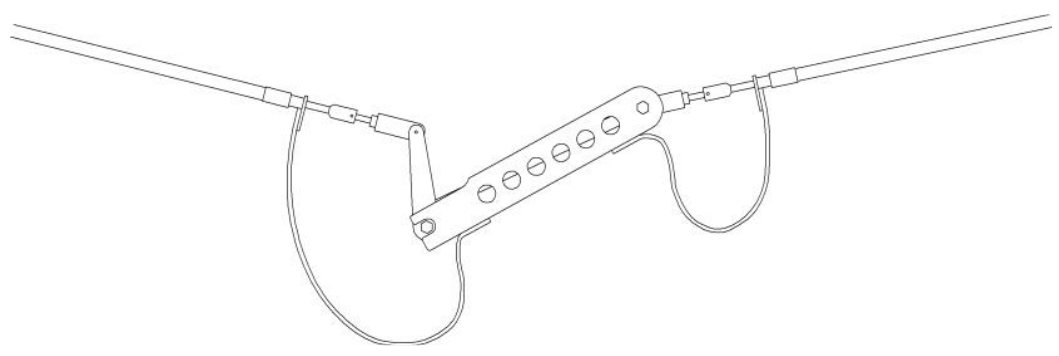

Figure 1. Thermal compensator "SLIM", designed in USA, simplified general view (USA patent US6864421B1).

\section{Ukrainian thermal compensator, principle of operation}

$a$

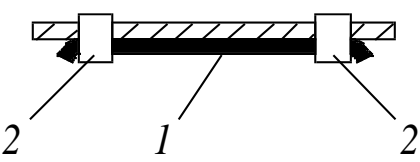

$b$

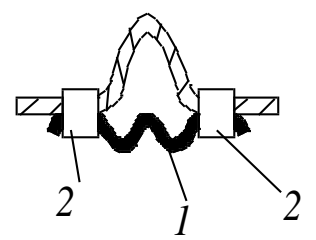

Figure 2. Principle of thermal compensation of an arc of sagging on power line, a)thermal compensator in the initial state; b) thermal compensator after triggering.

Using unique properties of SME material it became possible to have zero or negative extension of power line wire with increase in temperature [1,17]. A dependence between thermal compensator deformation and temperature is shown on Figure 3. 


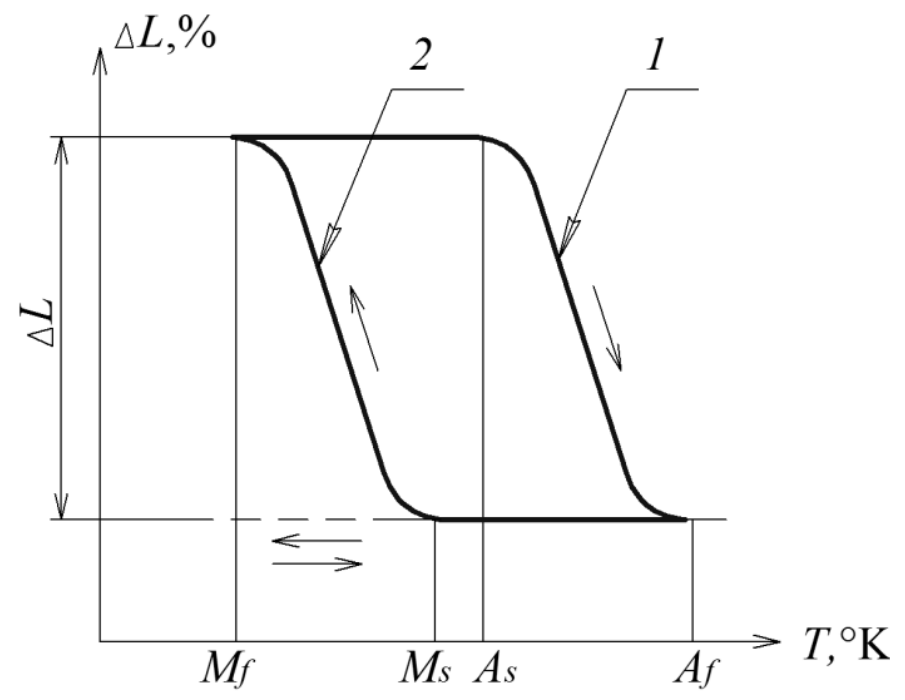

Figure 3. Dependence between SME element deformation and temperature, 1 - reverse transformation; 2 - direct transformation.

Thermosensitive element 1 is compressed at maximum temperature (Figure $2 b$ ), tension in the wire increases and sag decreases. If temperature of the wire drops below martensitic point (around $288^{\circ} \mathrm{K}$ ), thermosensitive element 1 loses its rigidity and under the influence of the weight of the wire straightens out (Figure 2b). At the next increase in temperature thermal compensator renews its shape (Figure 2b) $[1,15,17]$.

The temperature of the beginning and the end of the martensitic transformation, respectively $M_{s} \approx 282^{\circ} \mathrm{K}, M_{f} \approx 278^{\circ} \mathrm{K}$ (Figure 3 ) and the beginning and end of the reverse martensitic transformatin, respectively $A_{s} \approx 285^{\circ} \mathrm{K}, A_{f} \approx 306^{\circ} \mathrm{K}$. The shape of the curve of the dependence $\Delta L=f(T)$ is determined by the speed of heating and cooling.

Composition of the material with SME affects the magnitude of the hysteresis. Temperature of thermal compensator triggering depends on its load. That is the points for the same material are not stable and can shift by couple degrees $[2,4,12,17]$.

\section{Multifunctional thermal compensator of an arc of sagging on power line wires.}

Figure 4 schematically shows a thermal compensator, connected to two adjacent spans.

Wire 1 of the overhead power line is suspended on the towers. Minimum distance from the wires to the surface of the earth without the thermal compensator is indicated by $H_{0}$ (wire position 3), in the presence of the thermal compensator $-H_{l}$ (wire position 2) and $H_{2}$ (wire position 1). 


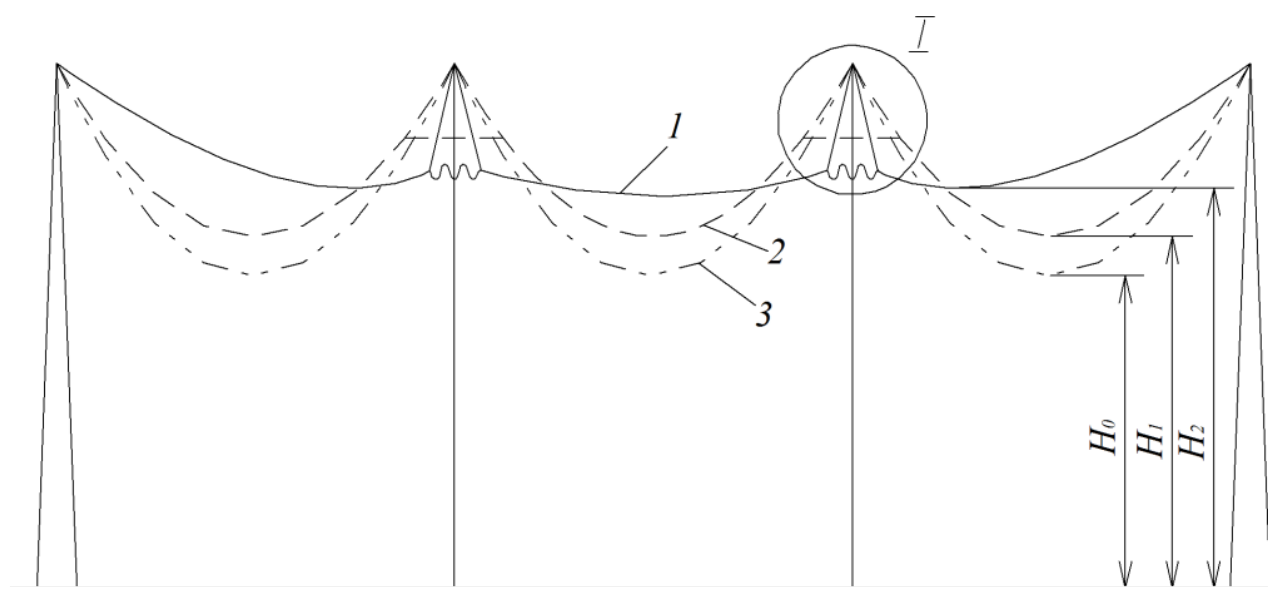

Figure 4. Influence of the thermal compensator on the minimum distance to the ground, $1,2,3$ - position of the wire depending on the thermal compensator operation.

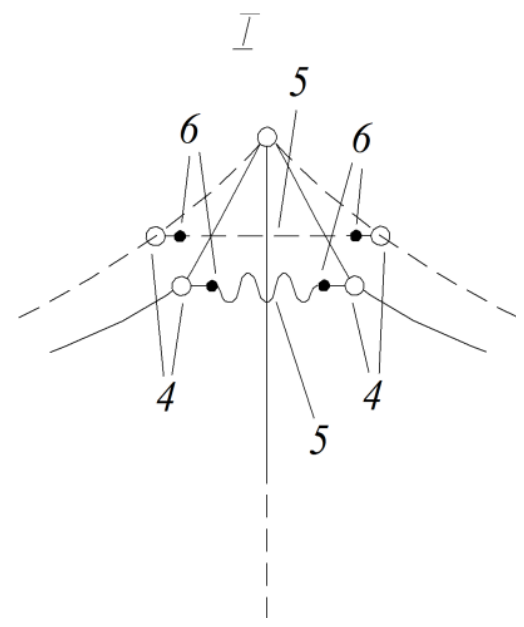

Figure 5. Fastening point of the thermal compensator,

4 - clamp, 5 - thermal compensator made from SME material, 6 - insulator.

Thermal compensator 5 is attached to the wire by the clamps 4 and insulating elements 6.

Since thermal compensator connects two spans of the wire, the force it perceives, is limited only by the horizontal component of the tension in the wire, which allows to significantly reduce the cost of materials for the thermal compensator. In addition, such method of thermal compensator connection, thanks to the flexible coupling of two adjacent spans of the wire gives an opportunity to influence the vibration of the wires. In this case, the energy of the oscillations of a wire in one span is transmitted to adjacent spans and summed there with the energy of oscillations of these spans. Since the energy transfer is carried out through a flexible thermal compensator, the amplitude, frequency and phase of the 
oscillations change, and the overlap of such oscillations leads to their weakening. Thus, the damping effect of the thermal compensators is similar to the action of vibration dampers $[2,4,15]$.

When wires are frosted, an additional energy source in the mobile laboratory can be connected to the thermal compensator. The rapid heating of the thermal compensator causes its compression. The wire from position 3 goes to position 1 . At the same time, snow and ice are removed from the wire. The insulating inserts 6 allows you to reduce the energy consumption of removing snow and ice that accumulates on the wires.

When examining the compined operation of the wire and the thermal compensator, made of SME material, we will use the piecewise-linear approximation of the performance characteristics of the thermal compensator (Figure 3).

When the air temperature increases, the length of the wire increases, tension in the wire decreases - upper part of the curve (Figure 3). When the ambient temperature reaches the temperature of the beginning of the reverse martensitic transformation of the thermal compensator, it begins to pull the wire by changing its own length [15,17]. With further increase in temperature, the wire continues to increase its length, and the thermal compensator - to decrease.

At the point $A_{f}$ thermal compensator completely restores its shape.

When temperature drops, thermal compensator keeps its shape because of its hysteresis $\left(A_{f}-M_{s}\right)$.

Lowering the temperature to the point of the beginning of a direct martensitic transformation (point $M_{s}$ ) causes deformation of the thermal compensator. Tension in the wire in the temperature range from the beginning of direct martensitic transformation (point $M_{s}$ ) to its end (point $M_{f}$ ) changes along the curve $M_{s}-M_{f}$. With further decrease in temperature, the thermal compensator does not participate in the work of the wire and the wire tension changes according to the natural characteristic [2,4].

In electrical grids, the dependence of the tension in the wire that came from the load and the temperature is expressed by the mathematical models.

Because of the fact that the characteristics of the thermal compensator are unambiguous, several equations are required to describe the operation of the wire with the thermal compensator according to Figure 3 and Figure $4[12,15,17]$.

For the section of characteristic of the material with SME $M_{f} \leq t \leq A_{s}$, where the thermal compensator does not significantly affect the work of the wire, the equation of the state of the wire is not different from the equation without the thermal compensator:

$$
\sigma-\frac{v^{2} \cdot E \cdot l^{2}}{24 \cdot \sigma^{2}}=\sigma-\frac{v^{2} \cdot E \cdot l^{2}}{24 \cdot \sigma_{0}^{2}}-\alpha \cdot E \cdot\left(t-t_{0}\right),
$$

where: $v_{0}$ - the specific load of the wire in its initial state;

$t_{0}$ - the temperature in the initial state;

$\sigma_{0}-$ tension at the lower point in the initial state;

$E$ - modulus of elasticity;

$\alpha$-temperature coefficient of linear elongation of the wire material;

$l-$ the length of the span;

$v, \sigma, t$ - specific load, tension, and temperature in the final state.

At the section of the characteristic $A_{s} \leq t \leq A_{f}$ (Figure 3, Figure 4) the thermal compensator triggers and restores its shape. This increases the tension in the wire and decreases the arc of sagging. Mathematical model of the state of the wire for the given range $[2,4]$ : 


$$
\begin{aligned}
& \text { Processes, Equipment and Control Systems- } \\
& \sigma-\frac{v^{2} \cdot E \cdot l^{2}}{24 \cdot \sigma^{2}}=\sigma_{0}-\frac{v_{0}^{2} \cdot E \cdot l^{2}}{24 \cdot \sigma_{0}^{2}}-\alpha \cdot E \cdot\left(t-t_{0}\right)-\frac{l_{k} \cdot \alpha_{k} \cdot E}{l} \cdot\left(t-A_{s}\right),
\end{aligned}
$$

where: $\alpha_{k}$-temperature coefficient of elongation of the thermal compensator.

$$
\alpha_{k}=\frac{\varepsilon}{100 \cdot \Delta t_{p h}}
$$

where: $\varepsilon$ - maximal elongation (compression) of the material with SME, \%;

$$
\Delta t_{p h} \text { - temperature range of phase transformation. }
$$

In the range $M_{s} \leq t \leq A_{f}$ temperature of the wire lowers but shape of the thermal compensator remains intact, because of its hysteresis. Mathematical model of the state of the wire for the given range:

$$
\sigma-\frac{v^{2} E l^{2}}{24 \sigma^{2}}=\sigma_{0}^{2}-\frac{v_{0} E l^{2}}{24 \sigma_{0}^{2}}-\alpha E\left(t-t_{0}\right)+\frac{\Delta l_{k} E}{l},
$$

where: $\Delta l_{k}$ - maximal compression of the thermal compensator.

In the range $M_{f} \leq t \leq M_{s}$ thermal compensator loses its elastic properties and under the influence of the weight of the wire straightens out [12,15,17].

In this case mathematical model of the state of the wire becomes:

$$
\sigma-\frac{v^{2} l^{2} E}{24 \sigma^{2}}=\sigma_{0}-\frac{v^{2} E \mathrm{I}^{2}}{24 \sigma_{0}^{2}}-\alpha E\left(t-t_{0}\right)-\frac{l_{k} \alpha_{k} E}{l}\left(t-M_{s}\right)
$$

Magnitude of the temperature induced elongation of the wires $\Delta l$, which needs to be compensated is always known. Therefore stroke of the thermal compensator is also known and it also equals $\Delta l$.

Because maximal permissible elongation of SME material is $\varepsilon$, the length of the thermal compensator will be:

$$
l_{k}=\frac{100 \cdot \Delta l}{\varepsilon}
$$

Second main requirement for the operation of the thermal compensator is equality of the force generated by thermal compensator $P_{k}$ and tension $T_{w}$ in the power line wire $[1,2,4]$ :

$$
P_{k}=F_{k} \sigma_{k}
$$

where: $F_{k}$ - cross-sectional area of the thermal compensator;

$\sigma_{k}$ - maximal force generated by the thermal compensator per unit of cross-sectional area.

After calculation of the cross-sectional area of the thermal compensator $F_{k}$, we can find the mass of the thermal compensator. In the case if $P_{k}<T_{\mathrm{w}}$ thermal compensator will not provide compensation of the wire elongation. The stroke of the thermal compensator will be less than $\Delta l$. If $P_{k}>T_{\mathrm{w}}$ thermal compensator will not return in the previous (deformed) sate.

Influence of the additional loads on the wire with the thermal compensator (e.g. wind) is not taken into account because the wire will be effectively cooled by the wind $[12,15,17]$. 


\section{Mechanical tension generated in the thermal compensator:}

$$
\sigma=\frac{\rho \Delta Q}{\varepsilon_{t}} \ln \frac{A_{f}}{A_{s}}
$$

where: $\rho$-density of the SME material,

$$
\varepsilon_{t}=\frac{l_{t}-l_{0}}{l_{0}}
$$

where: $l_{t}, l_{0}-$ the length of the SME element after heating and with initial temperature accordingly.

\section{Device for installing the thermal compensator on power line wires.}

The American thermal compensator (SLIM) may be installed between the tower and the suspended line, or may be installed within the span of the suspended line. The device may be installed using techniques similar to those used for installation of a "splice' or a "deadend" on such lines. The "splice' technique is achieved by cutting the line at two positions at a given distance from each other and installing the device by connecting the device ends to the cut ends of the line. In case of a "dead-end" technique, installation is achieved by cutting the power line at one location at a given distance from its end connecting point to a fixed structure, such as a tower, and installing the device between the cut location of the line and the fixed structure and connecting the ends of the device to the cut end of the line and the fixed structure. Also, multiple devices can be installed in series if needed by cutting longer pieces of the power line.

The Ukrainian variant of the thermal compensator uses special device for installing the thermal compensator on power line (Figure 6).

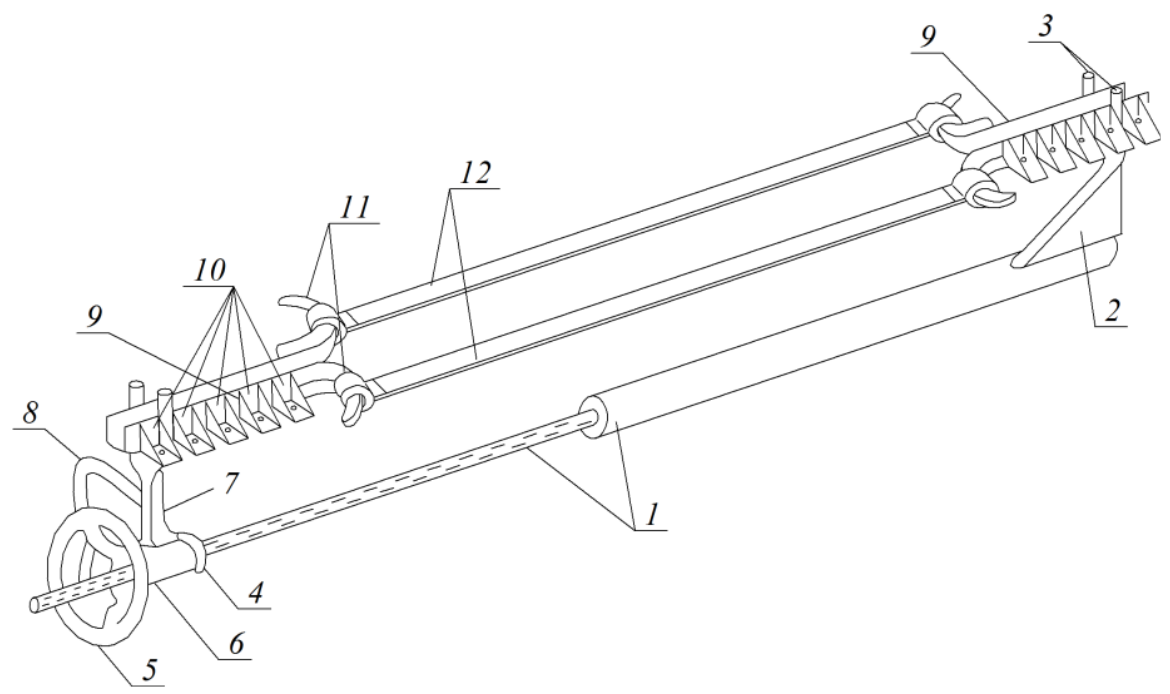

Figure 6. Installation device with thermal compensator on it. 
Simplification of the installation of the thermal compensators on the power line wires is achieved when the thermal compensator is preheated to the temperature of the end of the reverse martensitic transformation, the wire is pulled up by the magnitude of its absolute temperature extension in the given temperature range, regardless of the ambient temperature, and the thermal compensator is fastened to the wire loop, which appeared during the installation process $[2,4,17]$.

Due to the fact that the length of the thermal compensator is less than $1 \%$ of the length of the span, the influence of the temperature extension of the wire, parallel to which the thermal compensator attaches, can be neglected.

After installing the thermal compensator and releasing the wire, the thermal compensator will pull the wire and take one or another position, depending on the temperature of the wire and the environment, as well as the tension in the wire.

After the temperature lowers below the $M_{f}$, the thermal compensator will be deformed due to the tension in the wire (Figure 3).

The installation device with the thermal compensator installed is shown on Figure 6. The device consists of a rod 1, on one side it has a thread, on the other - a mounting bracket 2 with a fork 3 . On the threaded side there is a bushing 4 with an internal thread and a flywheel 5. On the bushing there is a coupling 6 with a bracket 7 and a fork. From the side of the coupling 6 and bracket 7 , handle 8 is placed. Forks planes are perpendicular to the rod 1 . Forks have semi-circular enclosures 9 (wire fastening points). Brackets 10 with holes, located symmetrically to the axis of the enclosure are attached to the lateral walls of the enclosures. The enclosure, on the one hand, has brackets 11, to which the power elements of the thermal compensator 12 are attached. The distance between the teeth of the forks is equal to the width of the enclosure 9, and the thickness of the teeth of the forks is equal to the distance between the side brackets $10[1,17]$.

The mounting point for the thermal compensator is shown on Figure 7.

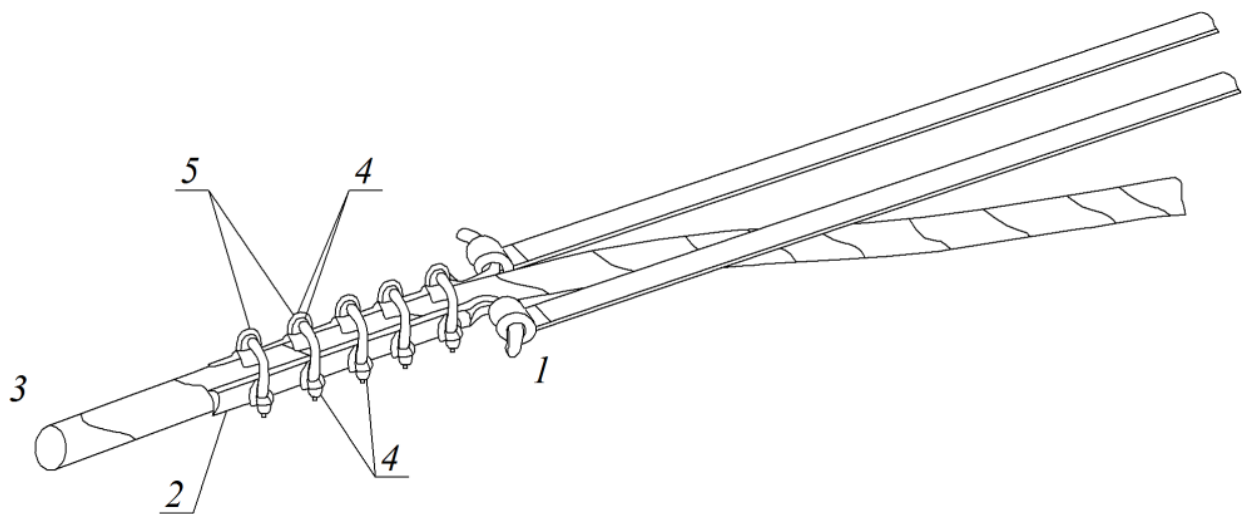

Figure 7. Thermal compensator mounting point, 1 - bracket, 2 - housing, 3 - wire, 4,5 - connection clamps.

The wire 3 passes through the housing 2. The tensioning bolts 4 with the dies 5 press the wire 3 to the housing 2 . The brackets 1 , located on one side of the housing 2, are located symmetrically to the geometric center of the wire 3 . 


\section{- Processes, Equipment and Control Systems-}

Usually the installation of a thermal compensator proceeds at a temperature higher than the temperature of the end of the direct martensitic transformation, which causes additional complications, since at such a temperature the thermal compensator is already beginning to recover its shape $[12,15,17]$.

\section{Conclusions}

1. Thermal compensator reduces wire sag automatically. Changes of the environment which induce the sag (temperature, force and direction of the wind, solar radiation) will act on the device which in response will reduce the wire sag.

2. Thermal compensator will reduce wire sag without need to replace the power line to a new one with bigger capacity or with lower characteristic of wires sag.

3. Thermal compensator will reduce wire sag without need to bundle conductors.

4. Thermal compensator will reduce wire sag without need to modificate the power line towers.

5. Thermal compensator will reduce wire sag which allows to construct power line towers on a bigger distance from one to another. This allows to construct smaller amount of tower.

6. Thermal compensator will reduce wire sag which allows to construct lower power line towers.

7. Thermal compensator will reduce wire sag without lowering the power line current.

8. Thermal compensator is a new class of power line hardware that solves the temperature induced elongation of the wires problem by using a material which reacts to temperature change by significantly changing its own size and geometry,

9. American thermal compensator was designed later than Ukrainian one. Authors in different ways were trying to bypass patent information of Ukrainian thermal compensator. This has led to complification of the thermal compensator design and as result to increased cost. It is worth noting that thermal compensators work in very harsh conditions. Reliability of the device with rotating parts is extremely low. The axles will fail during very first year of operation. Installation of an American thermal compensator requires cutting of the wire. This is labor-intensive work, that can lead to problems with power supplying. Ukrainian variant of installing the thermal compensator on power line is much more simple and cost efficient. Thermal compensator mounting point allows to increase reliability of the work of the wire.

\section{References}

1. Ukrayinets A., Shesterenko V. (2017), Innovative local control of alternating voltage, Ukrainian Journal of Food Science, 5(), pp. 305-318.

2. Shesterenko V., Mashchenko O., Romaniuk O. (2018), Optimization of external power delivering system of object by mechanical influence on the work of power line wires, Ukrainian Journal of Food Science, 6(1), pp. 127-135.

3. Shesterenko V.Ye. (2011), Systemy elektrospozhyvannia ta elektropostachannia promyslovykh pidpryiemstv, Nova knyha, Vinnytsia.

4. Shesterenko V.Ye. (2001), Optymizatsiia system elektrospozhyvannia promyslovykh pidpryiemstv, Hlana, Kyiv. 


\section{- Processes, Equipment and Control Systems-}

5. Shesterenko V.Ye., Shesterenko O.V. (2013), Elektropostachannia promyslovykh pidpryiemstv, Nova knyha, Kyiv.

6. Abhik Banerjee, V. Mukherjee, S.P. Ghoshal (2014), Intelligent fuzzy-based reactive power compensation of an isolated hybrid power system Original Research Article, International Journal of Electrical Power \& Energy Systems, 57, pp. 164-177.

7. Binod Shaw, V. Mukherjee, S.P. Ghoshal (2014), Solution of reactive power dispatch of power systems by an opposition-based gravitational search algorithm Original Research Article, International Journal of Electrical Power \& Energy Systems, 55, pp. 29-40.

8. Salles D., Jiang C., Xu W., Freitas W., Mazin H. E. (2012), Assessingthe collective harmonic impact of modern residential loads - Part I: Methodology, IEEE Trans. Power Del., 27(4), pp. 1937-1946.

9. Jiang C., Salles D., Xu W., Freitas W. (2012), Assessing the collective harmonic impact of modern residential loads - Part II: Applications, IEEE Trans. Power Del., 27(4), pp. 1947-1955.

10. Lihachev V.A., Kuz'min S.L., Kamenceva Z.P. (1987), Jeffekt pamjati formy, LGU, Leningrad, p.218.

11. Otsuka K., Wayman C.M. (1999), Shape Memory Materials, Cambridge University Press, New York, pp. 27-44.

12. Duerig T.W., Pelton A.R. (1994), Ti-Ni shape memory alloys, Materials Properties Handbook: Titanium Alloys, pp. 1035-1048.

13. K. Oocuka, K. Simidzu, Ju. Sudzuki i dr. (1990) Splavy s jeffektom pamjati formy, per. s japonskogo pod red. A.M. Glezera, Metallurgija, Moscow.

14. Barvinok V.A. et al. (1987), Malogabaritnoe oborudovanie i instrument s silovym privodom iz splava s pamjat'ju formy, prednaznachennye dlja vypolnenija remontnomontazhnyh rabot, Problemy kosmicheskoj tehnologii metallov, Trudy IJeS im. Patona, pp. 99-103.

15. Kornilov I.I. et al. (1977), Nikelid titana $i$ drugie splavy s jeffektom pamjati formy, Nauka, Moscow.

16. Barvinok V.A., Bogdanovich V.I., Lomovskoj O.V., Vishnjakov M.A., Groshev A.A. (2011), Razrabotka reversivnyh silovyh privodov iz materialov s jeffektom pamjati formy dlja ustrojstv, primenjaemyh $\mathrm{v}$ uzlah raschekovki kosmicheskih apparatov, Izvestija Samarskogo nauchnogo centra RAN, 13, 4(2), pp. 301-305.

17. Letenkov O.V., Filippov D.A. (2016), Raschet sistemy privoda: pruzhina iz materiala s jeffektom pamjati formy - kontrpruzhina, Mezhdunarodnyj nauchno - issledovatel'skij zhurnal, 11(53, 4), pp. 77-81.

18. Wilkes K.E., Liaw P.K. (2000), The fatigue behavior of shape-memory alloys, The Journal of The Minerals, Metals \& Materials Society (TMS), 52(10), pp. 45-46. 